\title{
Solidification and Precipitation Microstructure Simulation of a Hypereutectic Al-Mn-Fe-Si Alloy in Semi-Quantitative Phase-Field Modeling with Experimental Aid
}

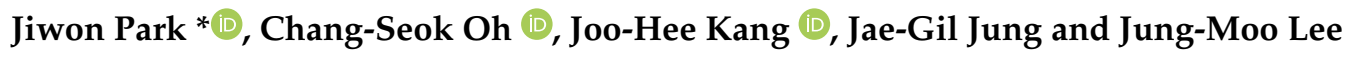 \\ Korea Institute of Materials Science, 797 Changwondaero, Changwon 51508, Korea; csoh@kims.re.kr (C.-S.O.); \\ joohee@kims.re.kr (J.-H.K.); jgjung@kims.re.kr (J.-G.J.); jmoolee@kims.re.kr (J.-M.L.) \\ * Correspondence: jiwonp@kims.re.kr; Tel.: +82-55-280-3372
}

Received: 17 September 2020; Accepted: 30 September 2020; Published: 3 October 2020

\begin{abstract}
In this study, microstructural evolution during solidification of a hypereutectic $\mathrm{Al}-\mathrm{Mn}-\mathrm{Fe}-\mathrm{Si}$ alloy was investigated using semi-quantitative two-/three-dimensional phase-field modeling. The formation of facetted $\mathrm{Al}_{6} \mathrm{Mn}$ precipitates and the temperature evolution during solidification were simulated and experimentally validated. The temperature evolution obtained from the phase-field simulation, which was balanced between extracted heat and latent heat release, was compared to the thermal profile of the specimen measured during casting to validate the semi-quantitative phase-field simulation. The casting microstructure, grain morphology, and solute distribution of the specimen were analyzed using electron backscatter diffraction and energy-dispersive spectroscopy and compared with the simulated microstructure. The simulation results identified the different Fe to $\mathrm{Mn}$ ratios in $\mathrm{Al}_{6}\left(\mathrm{Mn}_{x}, \mathrm{Fe}_{1-x}\right)$ precipitates that formed during different solidification stages and were confirmed by energy-dispersive spectroscopy. The precipitates formed in the late solidification stage were more enriched with Fe than the primary precipitate due to solute segregation in the interdendritic channel. The semi-quantitative model facilitated a direct comparison between the simulation and experimental observations.
\end{abstract}

Keywords: $\mathrm{Al}_{6} \mathrm{Mn}$; precipitation; phase-field modeling; microstructural analysis

\section{Introduction}

Precipitation behavior in $\mathrm{Al}$ alloys is of great interest due to its strong influence on the mechanical properties through a hardening effect [1-3]. Small changes in the concentrations of alloying elements or heat treatment conditions can readily alter the mechanical properties and product quality by modifying the microstructure. For example, $\mathrm{Mn}$ is alloyed in $\mathrm{Al}$ to enhance strength, formability, and corrosion resistance [4-6]. However, undesired formation of large, faceted Mn-containing precipitates in high-Mn content alloys can diminish the desired properties. In the context of materials tailored under a process-structure-property relationship, it is important to elucidate the microstructural evolution that results from the processing conditions. Recent advances in process-structure relationship modeling techniques [7] have made it possible to illustrate the underlying physical nature in an interpretable form.

The phase-field approach is now one of the most widely adopted methods in microstructural evolution and phase transformation modeling [8-16]. Combined with computational thermodynamic databases, it can quantitatively simulate the solidification microstructure of alloys with consideration of latent heat release during phase transformation, anisotropy of interfacial energy and mobility. Wang et al. [14] simulated the three-dimensional (3D) growth morphology of the primary Si precipitate phase in hypereutectic Al-Si alloys using the phase-field approach. The proposed interface anisotropy 
model successfully illustrated the formation of faceted Si grains, which was validated by comparison with scanning electron microscopic (SEM) images. Köhnen et al. [17] conducted two-dimensional (2D) phase-field simulation to examine the elemental distribution and epitaxial growth of solidification in additively manufactured X30Mn21 powder. Although phase-field modeling proved its functionality in solidification simulations, the literatures focuses on examining a few features of the method such as a precipitate morphology evolution without an interaction with matrix phase [14], 2D growth under rapid solidification conditions [17], 3D simulation in a binary alloy [15], or without considering solute redistribution [16].

In addition, most studies on the precipitation of $\mathrm{Al}$ alloys were carried out in the hypoeutectic region, where the precipitate forms as a secondary phase in the Al matrix [4-6,18]. In this study, microstructural evolution during solidification of a hypereutectic Al-Mn-Fe-Si alloy was studied with regard to the morphology and chemistry of the precipitates using the phase-field approach with experimental aid. To effectively capture the microstructural evolution, the thermal history during solidification was used as a primary process condition for the simulations. This approach utilized direct comparisons between the measured and the simulated temperature evolution, and resulting microstructures in semi-quantitative manner. The simulation results elucidated the phase evolution of multi-component/multi-phase alloy during solidification in each time/temperature step.

\section{Materials and Methods}

The phase-field model utilizes the phase-field parameter $\phi=\phi(\vec{x}, t)$ to represent the temporal/spatial evolution of phases and the corresponding microstructural changes. The multiphase-field approach proposed by Steinbach et al. [9,19] was implemented in MICRESS [20], a phase-field solver, to simulate the microstructural evolution in multi-component, multi-phase alloys which was used in this work. When coupled with CALPHAD (CALculation of PHAse Diagrams)-type thermodynamic and kinetic databases, it has effectively facilitated kinetic simulations in various systems $[8,11,13,14]$. In this model, the evolution of multiphase-field parameter can be described using the following equation:

$$
\frac{\partial \phi_{\alpha}}{\partial t}=\sum_{\beta \neq \alpha}^{v} M_{\alpha \beta}^{\phi}\left[b \Delta G_{\alpha \beta}-\sigma_{\alpha \beta}\left(K_{\alpha \beta}+A_{\alpha \beta}\right)+\sum_{\gamma \neq \alpha \neq \beta}^{v} j_{\alpha \beta \gamma}\right],
$$

where, $M_{\alpha \beta}^{\phi}$ is the phase-field mobility, $\Delta G_{\alpha \beta}$ is the thermodynamic driving force, $K_{\alpha \beta}$ is the curvature term, $A_{\alpha \beta}$ is the interface anisotropy where $0 \leq \phi_{i} \leq 1$ and $\sum_{\alpha} \phi_{\alpha}=1$ are always satisfied, $b$ is the numerical weight constant, and $j_{\alpha \beta \gamma}$ is the triple-junction term. In this study, two types of interface anisotropy were applied to depict the different growth natures of dendritic $\mathrm{Al}$ grains and $\mathrm{Al}_{6} \mathrm{Mn}$ precipitates. Interfacial stiffness $\left(\sigma^{*}\right)$ and mobility $(\mu)$ anisotropy functions for $\mathrm{Al}$ grains are defined as follows [21]:

$$
\begin{aligned}
& a_{\sigma^{*}}^{A l}=1-\delta_{\sigma^{*}} \cdot 4 \cdot\left(n_{x}^{4}+n_{y}^{4}+n_{z}^{4}-0.75\right), \\
& a_{\mu}^{A l}=1+\delta_{\mu} \cdot 4 \cdot\left(n_{x}^{4}+n_{y}^{4}+n_{z}^{4}-0.75\right),
\end{aligned}
$$

where $\vec{n}=\left(n_{x}, n_{y}, n_{z}\right)$ is the interface normal vector, and the coefficients $\delta_{\sigma^{*}}$ and $\delta_{\mu}$ were set to 0.05 for both. Similarly, anisotropy functions for faceted $\mathrm{Al}_{6} \mathrm{Mn}$ were defined as follows [21]:

$$
\begin{gathered}
a_{\sigma^{*}}^{A l_{6} M n}(\theta)=\left[\delta_{\sigma^{*}}+\left(1-\delta_{\sigma^{*}}\right) \cdot \tan |\theta| / \kappa \cdot \tanh (\kappa / \tan |\theta|)\right]^{-1}, \\
a_{\mu}^{A l_{6} M n}(\theta)=\delta_{\mu}+\left(1-\delta_{\mu}\right) \cdot \tan |\theta| / \kappa \cdot \tanh (\kappa / \tan |\theta|),
\end{gathered}
$$

where $\theta$ is the angle between $\vec{n}$ and the pre-defined facet vector, and the coefficients $\delta_{\sigma^{*}}, \delta_{\mu}$, and $\kappa$ were set to $0.7,0.5$, and 0.75 , respectively. Pre-defined $\{101\}$ facet planes of octahedral $\mathrm{Al}_{6} \mathrm{Mn}$ were adopted in accordance with Kang et al. [22] and Yang et al. [23]. The nucleation of the precipitates followed 
a model proposed by Greer et al. [24] which is widely used in phase-field simulations involving the nucleation of phases $[10,25,26]$. The onset of the nucleation and growth of the precipitate occurred when a seed of precipitate achieved the desired undercooling which is inversely proportional to the seed radius. The size distribution of the precipitate seeds was taken from the positive tail of a normal distribution as shown in Figure 1. The given distribution was determined to depict reasonable primary precipitate distribution and to be compatible with the experimental observations.

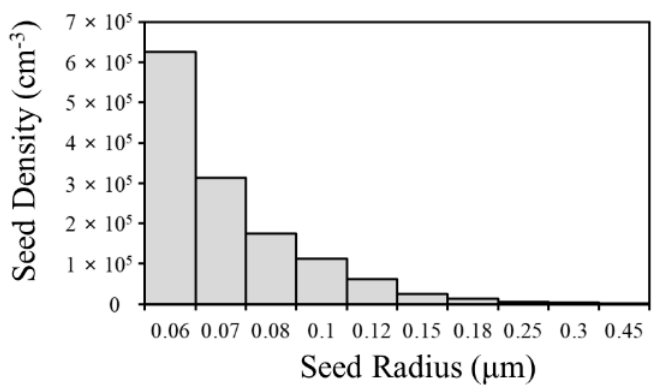

Figure 1. Size distribution of the precipitate seed.

During solidification, the overall heat flux is a balance between the heat extraction upon cooling and the latent heat released upon phase transformation when the geometrical interferences are neglected. Therefore, the temperature change (dT) can be calculated as [27].

$$
\mathrm{dT}=\frac{1}{\bar{c}_{p}}(\dot{q} d t-d L)
$$

where $\dot{q}$ is the heat extracted per unit volume, $\bar{c}_{p}$ is the average heat capacity, and $d L$ is the latent heat contribution which is given by the transformation kinetics. Consequently, a semi-quantitative kinetic simulation can be achieved by comparing experimental and simulated domain temperature evolution. The TCAL6 [28] and MOBAL5 [29] databases from Thermo-Calc software [30] were coupled with phase-field simulations through the TQ-Interface to perform the thermodynamic and diffusion calculations, respectively.

A hypereutectic Al-Mn alloy was melted at $1003 \mathrm{~K}$ in an electric furnace, degassed using an Ar gas bubbling filtration, and poured into a steel mold preheated to $473 \mathrm{~K}$. The chemical composition of the specimen is listed in Table 1 that was analyzed by Inductively Coupled Plasma Optical Emission Spectroscopy (ICP-OES) using an Agilent 5100/5110 VDV ICP-OES (Agilent, Santa Clara, CA, USA). The temperature evolution of the cast was measured by Type-K thermocouples directly inserted into the melt (see Supplementary Material for the detailed design). The measured temperature profile was used as a primary process parameter in the phase-field simulations. The initial cooling rate near the pouring temperature was $13.5 \mathrm{~K} / \mathrm{s}$. The microstructure of the as-cast specimen was analyzed by scanning electron microscopy (SEM), electron backscatter diffraction (EBSD), and energy-dispersive spectroscopy (EDS) using a JSM-7900F microscope (JEOL Ltd., Tokyo, Japan) equipped with Symmetry EBSD (Oxford Instruments NanoAnalysis, High Wycombe, UK) and an X-Max 150mm² EDS module (Oxford Instruments NanoAnalysis, High Wycombe, UK). The accelerating voltage was $15 \mathrm{kV}$ for the EBSD and EDS analyses. The obtained EBSD-EDS micrographs were analyzed using Aztec (4.3, Oxford Instruments NanoAnalysis, High Wycombe, UK and OIM Analysis (8.1, EDAX LLC, Mahwah NJ, USA) software to determine the orientation characteristics and grain size statistics.

Table 1. Chemical composition of the as-cast alloy specimen analyzed by Inductively Coupled Plasma Optical Emission Spectroscopy (ICP-OES).

\begin{tabular}{ccccccc}
\hline Element & Al & Mn & Fe & Si & Zn & Ti \\
\hline Composition $(w t \%)$ & Bal. & 2.7 & 0.2 & 0.07 & 0.01 & 0.02 \\
\hline
\end{tabular}




\section{Results and Discussion}

During the solidification of the hypereutectic Al-2.7Mn-0.2Fe-0.07Si alloy, four major phases were expected to appear in the following sequence from the equilibrium phase fraction and Scheil-Gulliver calculations as shown in Figure 2 : liquid $\rightarrow$ liquid $+\mathrm{Al}_{6} \mathrm{Mn} \rightarrow$ liquid $+\mathrm{Al}_{6} \mathrm{Mn}+\alpha-\mathrm{Al} \rightarrow$ liquid + $\mathrm{Al}_{6} \mathrm{Mn}+\alpha-\mathrm{Al}+\alpha-\mathrm{Al}(\mathrm{Mn}, \mathrm{Fe}) \mathrm{Si}$. After solidification is complete, $\mathrm{Al}_{12} \mathrm{Mn}$ forms from solid state phase transformation out of $\alpha$-Al at temperatures below $547 \mathrm{~K}$; however, this is beyond the scope of this work. In the stoichiometric $\mathrm{Al}_{6} \mathrm{Mn}$ precipitate phase, the Mn sublattice site is partially occupied by Fe to form $\mathrm{Al}_{6}\left(\mathrm{Mn}_{x}, \mathrm{Fe}_{1-x}\right)$. The Fe-to-Mn ratio in the precipitate increases as solidification proceeds due to the limited solubility of Fe in the $\alpha$-Al phase and subsequent Fe-enrichment in the interdendritic melt channel.

(a)

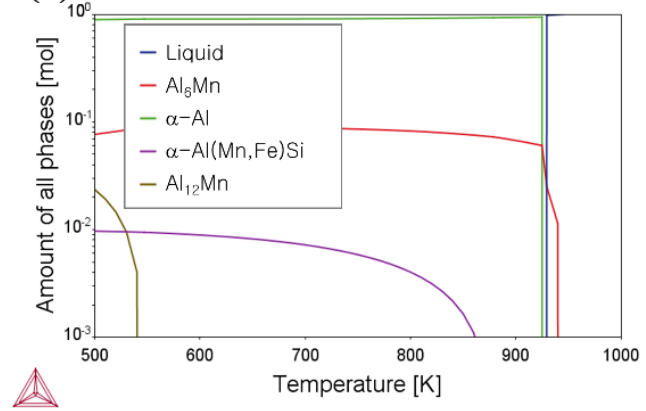

(b)

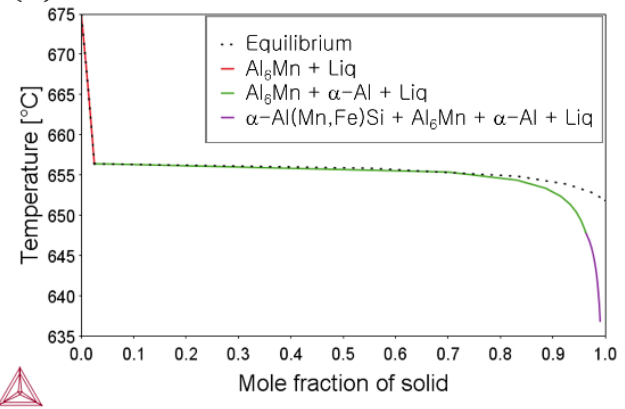

Figure 2. (a) Equilibrium phase fraction change with temperature (b) Scheil-Gulliver solidification calculation.

The microstructure of the as-cast specimen was analyzed by backscattered electron (BSE) imaging and EBSD, as shown in Figure 3. The low and high magnification BSE micrographs presented in Figure $3 \mathrm{a}$,b reveal three distinctive types of precipitate: large, faceted $\mathrm{Al}_{6} \mathrm{Mn}$ primarily formed during solidification; fragmented $\mathrm{Al}_{6} \mathrm{Mn}$ in the interdendritic channel; and fine-dispersed $\mathrm{Al}_{12} \mathrm{Mn}$ in the matrix. Two $\mathrm{Al}_{6} \mathrm{Mn}$ precipitates formed in different solidification stages and exhibited different Fe-to-Mn ratios in the EDS analysis (Table 2). The average site fraction determined from the Mn-to-Fe ratio was $\mathrm{Al}_{6}\left(\mathrm{Mn}_{0.80}, \mathrm{Fe}_{0.20}\right)$ for precipitates in the interdendritic channel, which is due to the enrichment of Fe rejected from the $\alpha-\mathrm{Al}$ solidification front in the residual melt. On the other hand, the primary precipitate exhibited $\mathrm{Al}_{6}\left(\mathrm{Mn}_{0.91}, \mathrm{Fe}_{0.09}\right)$ which is close to the Mn-to-Fe ratio in the nominal composition. The Al content measured in the smaller precipitates was higher than the stoichiometric content, which was caused by the interaction of the electron beam with the matrix beneath the precipitates. Figure 4 shows the precipitate distribution and the grain shapes analyzed with EBSD. The average $\alpha$-Al grain size measured with EBSD was $357 \pm 140 \mu \mathrm{m}$, where small precipitates occupying less than 15 pixels were excluded from the grain size calculation. This value was used to determine the $2 \mathrm{D}$ and $3 \mathrm{D}$ simulation domain sizes in the phase-field simulations.

Table 2. EDS point and linescan data from Figure 3b. $x$ denotes the site fraction of $\mathrm{Mn}$ in $\mathrm{Al}_{6}\left(\mathrm{Mn}_{x}, \mathrm{Fe}_{1-x}\right)$ precipitate.

\begin{tabular}{|c|c|c|c|c|c|c|c|c|c|c|}
\hline \multirow{2}{*}{ Element ( $w t \%)$} & \multicolumn{9}{|c|}{ Point ID } & \multirow{2}{*}{ Averaged Profile in Figure $3 b$} \\
\hline & 1 & 2 & 3 & 4 & 5 & 6 & 7 & 8 & 9 & \\
\hline $\mathrm{Al}$ & 81.67 & 82.65 & 79.05 & 80.24 & 77.66 & 82.19 & 83.17 & 81.99 & 83.72 & 69.46 \\
\hline $\mathrm{Mn}$ & 15.13 & 14.15 & 14.28 & 15.55 & 17.59 & 13.93 & 14.23 & 13.89 & 14.80 & 2.64 \\
\hline $\mathrm{Fe}$ & 3.20 & 3.20 & 6.67 & 4.21 & 4.75 & 3.87 & 2.60 & 4.12 & 1.48 & 27.90 \\
\hline$x$ & 0.83 & 0.82 & 0.69 & 0.79 & 0.79 & 0.79 & 0.85 & 0.77 & 0.91 & 0.91 \\
\hline
\end{tabular}




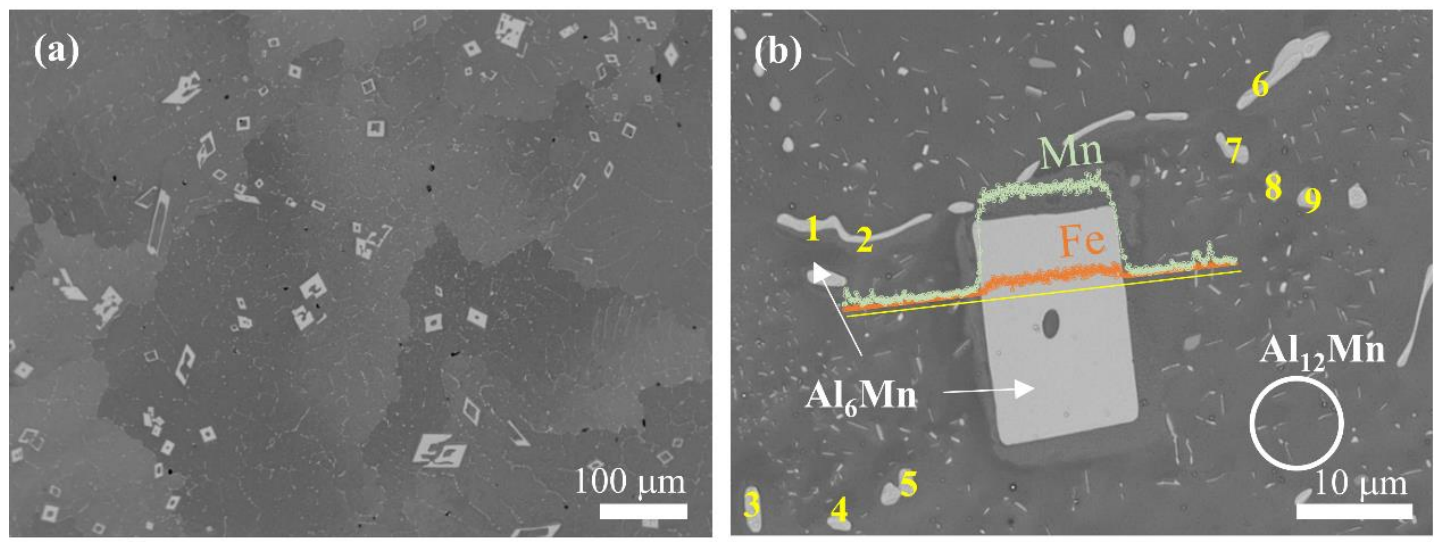

Figure 3. Backscattered electron (BSE) micrographs (a) low-magnification image (b) high-magnification image with energy-dispersive spectroscopy (EDS) linescan profiles along the yellow line.

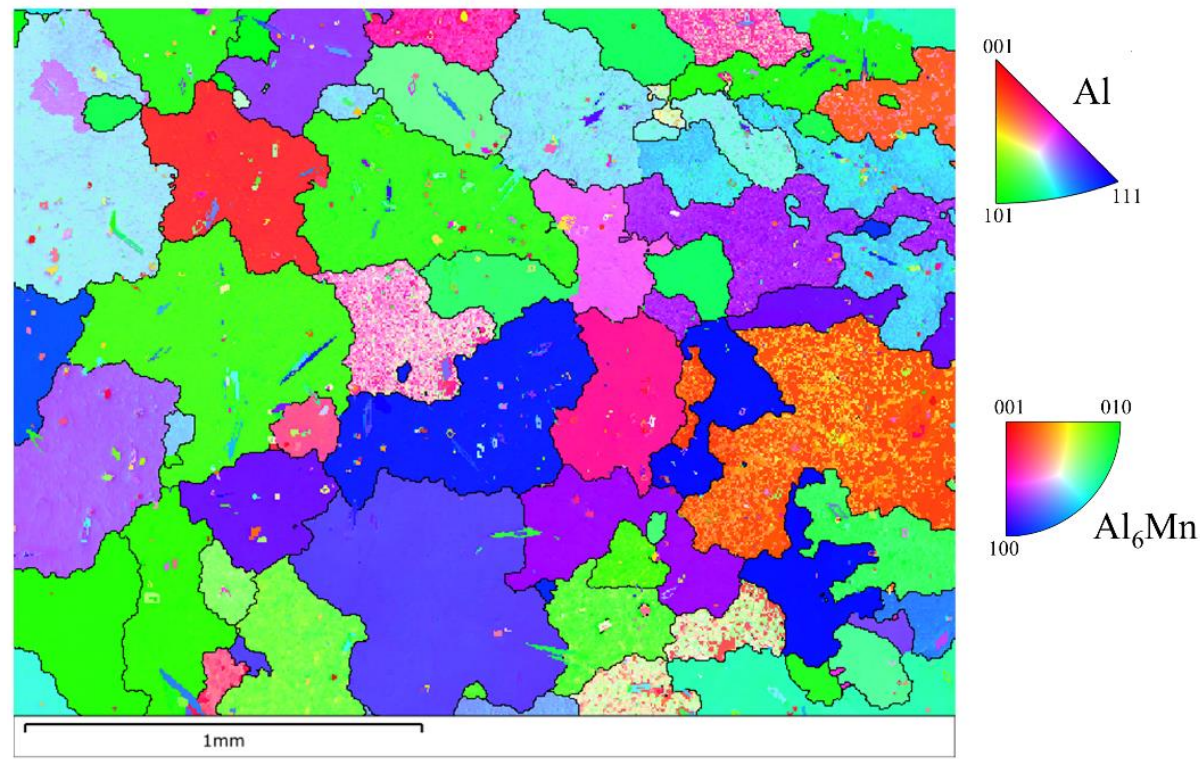

Figure 4. Orientation map analyzed with EBSD where black line indicates grain tolerance angle over 5 degrees.

Microstructural evolution during solidification is closely related to the thermal history of the system. The temperature change can be roughly estimated by Equation (6) with reasonable assumptions of the nucleation and transformation kinetics. Since the expected total phase fraction of the precipitates was determined to be less than $8 \mathrm{~mol} \%$ in the Scheil-Gulliver simulation, the latent heat contribution mainly came from the phase transition between liquid and $\alpha$-Al. Based on the thermal history estimated from the measured temperature profile, 2D and 3D phase-field simulations were conducted. In the simulations, two major solid phases were considered to be formed from the liquid phase: $\mathrm{Al}_{6} \mathrm{Mn}$ precipitate and $\alpha$-Al matrix. The formation of $\alpha-\mathrm{Al}(\mathrm{Mn}, \mathrm{Fe}) \mathrm{Si}$ was neglected since the expected phase fraction was less than $0.1 \mathrm{~mol} \%$ and the phase was not observed in the microscopic analysis. Primary and interdendritic $\mathrm{Al}_{6} \mathrm{Mn}$ precipitates were assigned to have identical phase-field indexes and were distinguished by their Fe contents.

Figure 5a compares the simulated and experimentally measured temperature profiles. The related simulation parameters are listed in Table 3. Due to the limitation of the available study on the phase interactions in hypereutectic Al-Mn system, interface energies were set to be similar to the Al-Si system [14] which exhibits faceted precipitates. Interface mobilities were set to be fast enough to maintain a diffusion-controlled solidification regime. The nucleation kinetics of the primary precipitate were not discernable in both the simulated and measured temperature profiles, while recalescence and 
the extended temperature arrest near the eutectic temperature were evident, which can be attributed to the formation of the solid $\alpha-\mathrm{Al}$ phase. As shown in Figure 5b, during microstructural evolution, over time, nucleation and growth of the primary precipitate do not pose significant effects on the temperature evolution. Meanwhile, the formation of $\alpha-\mathrm{Al}$ (colored in red in the phase map) was found to have significant delay on cooling. The primary precipitates continued to grow with faceted shapes until they were captured in the solid $\alpha-\mathrm{Al}$ phase as the solubility and the diffusion of Mn and Fe in solid $\mathrm{Al}$ are limited. When the fully solidified microstructure was compared with the EBSD phase map, as shown in Figure $5 c$, the simulated results effectively depicted the morphological characteristics of the grain and phase distributions. The elongated precipitates seen in Figures 4 and $5 c$ were not considered in the simulations since these precipitates exhibit similar chemical constitution to the faceted primary precipitate. Due to the limited solubility of Fe and Si in the solid $\alpha$-Al phase, most of them were segregated in the interdendritic channels as shown in Figure 6.

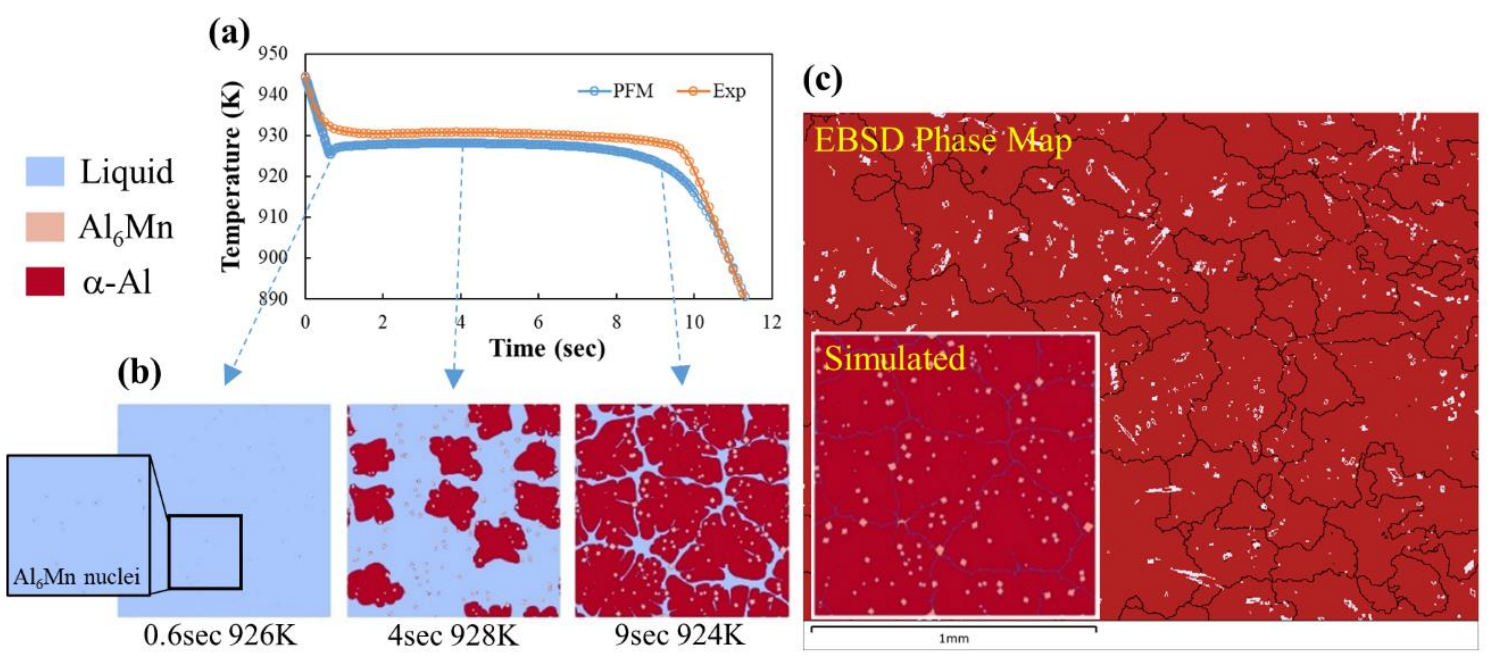

Figure 5. (a) Simulated and measured temperature profiles (b) 2D simulated microstructural evolution (c) observed using EBSD and simulated phase maps in scale-matched form.

Table 3. Phase-field simulation parameters.

\begin{tabular}{ccc}
\hline Parameter & Value & Unit \\
\hline Simulation grid size & 1 & $\mu \mathrm{m}$ \\
2D simulation domain size & $1000 \times 1000$ & $\mu \mathrm{m}^{2}$ \\
3D simulation domain size & $125 \times 125 \times 125$ & $\mu \mathrm{m}^{3}$ \\
Interface thickness & 3.0 & $\mathrm{cells}$ \\
Heat extraction rate & $8.8 \times 10^{7}$ & $\mathrm{~J} / \mathrm{s} \cdot \mathrm{m}^{3}$ \\
$\sigma_{\text {liq }-A l}$ & 0.09 & $\mathrm{~J} / \mathrm{m}^{2}$ \\
$\mu_{\text {liq-Al }}$ & $10^{-10}$ & $\mathrm{~m}^{4} / \mathrm{J} \cdot \mathrm{s}$ \\
$\sigma_{\text {liq-ppt }}$ & 0.5 & $\mathrm{~J} / \mathrm{m}^{2}$ \\
$\mu_{\text {liq-ppt }}$ & $10^{-12}$ & $\mathrm{~m}^{4} / \mathrm{J} \cdot \mathrm{s}$ \\
$\sigma_{A l-p p t}$ & 0.2 & $\mathrm{~J} / \mathrm{m}^{2}$ \\
$\mu_{A l-p p t}$ & $10^{-9}$ & $\mathrm{~m} / \mathrm{J} \cdot \mathrm{s}$ \\
\hline
\end{tabular}

To resolve the difference between the primary and interdendritic precipitates, a 3D simulation was conducted with a domain size of $125 \times 125 \times 125 \mu \mathrm{m}^{3}$. An $\alpha$-Al nucleus was placed in the corner of the domain, and the symmetric boundary conditions for the $\mathrm{x}, \mathrm{y}$, and $\mathrm{z}$ directions were applied based on the cubic symmetry of the face-centered cubic $\alpha$-Al phase. This configuration gave a diagonal $\alpha-\mathrm{Al}$ grain size of $433 \mu \mathrm{m}$, which sufficiently covers the average grain size estimated in the EBSD analysis. The simulation results presented in Figure 7 show well-defined facet planes of the primary precipitates, supporting the current model used in the simulations. After the primary precipitates randomly 
nucleated and grew, an $\alpha-\mathrm{Al}$ nucleus appeared in the bottom-left corner. Finally, small precipitates appeared in the interdendritic channel. The largest precipitate size was $55.2 \mu \mathrm{m}$, which is a reasonable value compared with the experimental observations. Figure 8 shows the Mn and Fe distribution of the region where the corresponding phase is indexed as $\mathrm{Al}_{6} \mathrm{Mn}$. An increase in the Fe concentration is evident moving from the bottom-left corner to top-right according to the shift of the $\alpha$-Al solidification front. The stoichiometry of the primary precipitate was found to be $\mathrm{Al}_{6}\left(\mathrm{Mn}_{0.94}, \mathrm{Fe}_{0.06}\right)$, which is similar to the initial liquid concentration ratio. The interdendritic precipitate, $\mathrm{Al}_{6}\left(\mathrm{Mn}_{0.82}, \mathrm{Fe}_{0.18}\right)$, showed a higher Fe content, similar to the value measured with EDS. The limited solubility of Fe in the solid $\alpha$-Al phase induced severe segregation of Fe in the interdendritic liquid channel, which led to the formation of Fe-concentrated precipitate in the last stage of solidification.
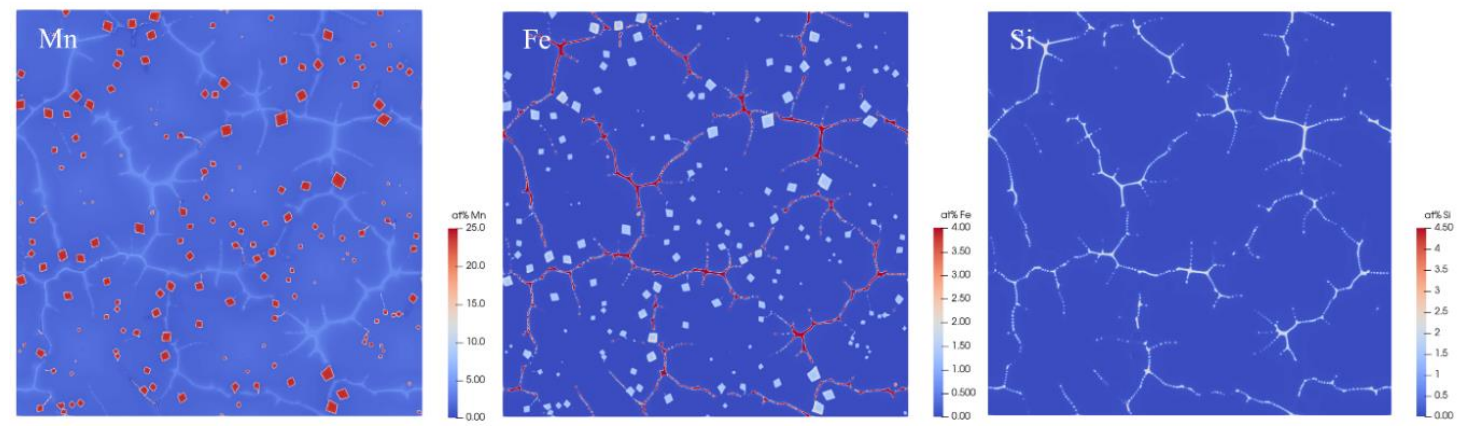

Figure 6. Simulated elemental distributions.
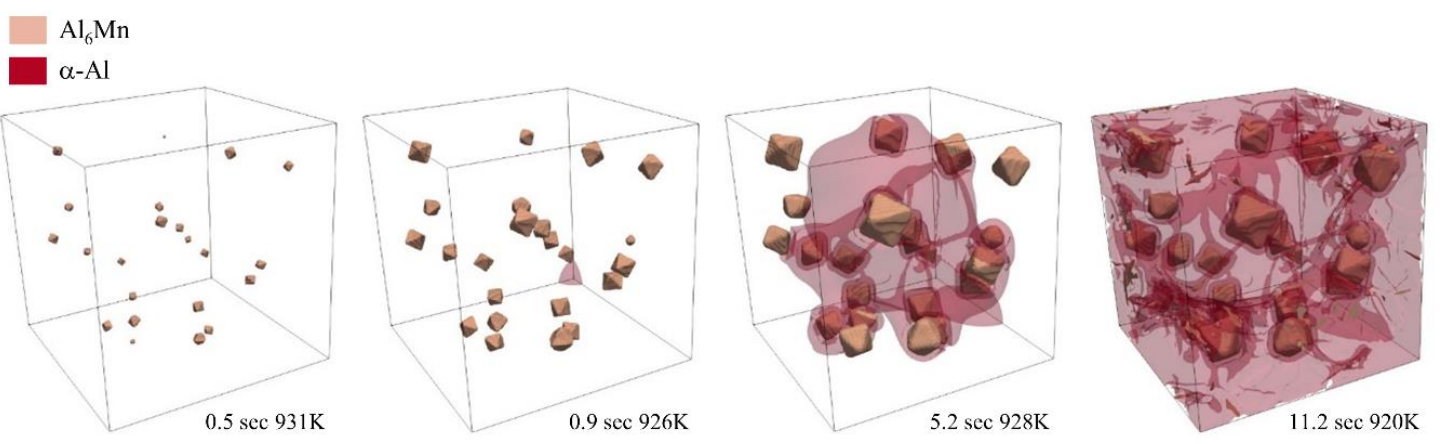

$125 \times 125 \times 125 \mu \mathrm{m}^{3}$

Figure 7. 3D simulated microstructural evolution.
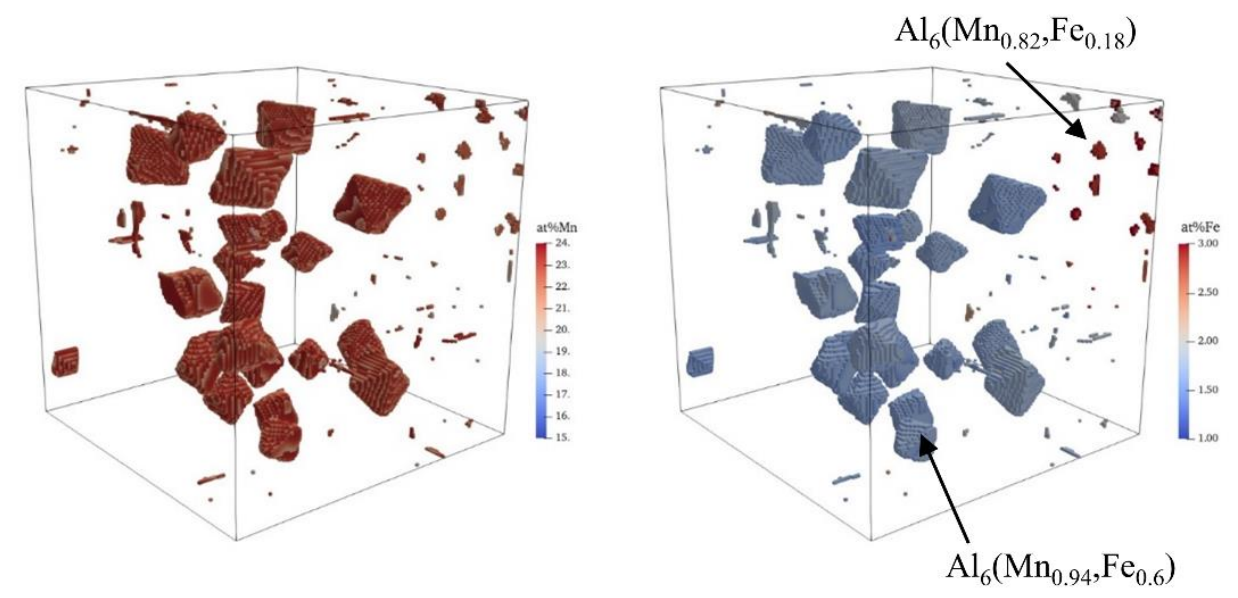

Figure 8. Mn and Fe distributions in the precipitates when the solidification was completed. 


\section{Conclusion}

In summary, 2D and 3D phase-field simulations were conducted to investigate the microstructural evolution during solidification in a hypereutectic Al-Mn-Fe-Si alloy. The applied model successfully demonstrated the formation of the faceted precipitate morphology and the different Mn-to-Fe ratios of the precipitates formed in the different solidification stages. Due to the strong segregation of the alloying elements in the liquid phase, the precipitate that formed in the interdendritic channel exhibited a higher Fe content than the primary precipitate. The semi-quantitative simulations, which adopted the thermal history of the specimen as the simulation condition, allowed for a direct comparison between the measured and the simulated temperature evolution reflecting latent heat release and recalescence during the solidification process. The simulated results containing information about the spatial distribution of the phases and compositions obtained with proper consideration of the process conditions can be transferred to future methods for further integrated process-structure-property simulations.

Supplementary Materials: The following are available online at http://www.mdpi.com/2075-4701/10/10/1325/s1, Figure S1: Construction design details of the casting mold, Figure S2: Simulation scheme, Figure S3: Precipitate size distribution at the end of simulation $(\mathrm{t}=11.2 \mathrm{~s}, \mathrm{~T}=920 \mathrm{~K})$.

Author Contributions: Conceptualization, J.P. and C.-S.O.; methodology, J.P. and J.-M.L.; validation, J.P., J.-H.K. and C.-S.O.; formal analysis, J.P. and J.-H.K.; investigation, J.P. and C.-S.O.; resources, J.-G.J.; writing-original draft preparation, J.P.; writing-review and editing, J.-H.K., C.-S.O. and J.-G.J.; supervision, C.-S.O.; All authors have read and agreed to the published version of the manuscript.

Funding: This research was funded by the Fundamental Research Program of Korea Institute of Materials Science, grant number PNK7070 and the National Research Foundation of Korea, grant number 2020R1A2C2008416. The APC was funded by Korea Institute of Materials Science.

Conflicts of Interest: The authors declare no conflict of interest.

\section{References}

1. Andersen, S.J.; Marioara, C.D.; Friis, J.; Wenner, S.; Holmestad, R. Precipitates in aluminium alloys. Adv. Phys. X. 2018, 3, 1479984. [CrossRef]

2. Fine, M.E. Precipitation hardening of aluminum alloys. Metall. Trans. A 1975, 6, 625-630. [CrossRef]

3. Li, Y.; Gao, G.; Wang, Z.; Di, H.; Li, J.; Xu, G. Effects of the Mg/Si ratio on microstructure, mechanical properties, and precipitation behavior of Al-Mg-Si-1.0 wt\%-Zn alloys. Materials 2018, 11, 2591. [CrossRef] [PubMed]

4. Liu, K.; Chen, X.-G. Evolution of Intermetallics, Dispersoids, and Elevated Temperature Properties at Various Fe Contents in Al-Mn-Mg 3004 Alloys. Metall. Mater. Trans. B 2016, 47, 3291-3300. [CrossRef]

5. Liu, K.; Chen, X.-G. Evolution of microstructure and elevated-temperature properties with Mn addition in Al-Mn-Mg alloys. J. Mater. Res. 2017, 32, 2585-2593. [CrossRef]

6. Zhang, Y.; Jin, W.; Hao, X.; Qiu, F.; Zhao, Q. Improving Elevated-Temperature Strength of an Al-Mn-Si Alloy by Strain-Induced Precipitation. Metals 2018, 8, 446. [CrossRef]

7. Schmitz, G.J.; Prahl, U. Handbook of Software Solutions for ICME; Wiley-VCH Verlag GmbH \& Co. KGaA.: Weinheim, Germany, 2017; pp. 23-30.

8. Eiken, J.; Apel, M.; Liang, S.-M.; Schmid-Fetzer, R. Impact of P and Sr on solidification sequence and morphology of hypoeutectic Al-Si alloys: Combined thermodynamic computation and phase-field simulation. Acta Mater. 2015, 98, 152-163. [CrossRef]

9. Eiken, J.; Böttger, B.; Steinbach, I. Multiphase-field approach for multicomponent alloys with extrapolation for numerical application. Phys. Rev. E. 2006, 73, 066122. [CrossRef]

10. Monas, A.; Shchyglo, O.; Kim, S.-J.; Yim, C.D.; Höche, D.; Steinbach, I. Divorced eutectic solidification of Mg-Al alloys. JOM 2015, 67, 1805-1811. [CrossRef]

11. Viardin, A.; Zollinger, J.; Sturz, L.; Apel, M.; Eiken, J.; Berger, R.; Hecht, U. Columnar dendritic solidification of TiAl under diffusive and hypergravity conditions investigated by phase-field simulations. Comput. Mater. Sci. 2020, 172, 109358. [CrossRef]

12. Wang, I.; Wei, Y. Onset of curved dendrite growth in an Al-Cu welding pool: A phase field study. JOM 2018, 70, 733-738. [CrossRef] 
13. Wei, M.; Zhang, L.; Yang, M.; Li, K.; Liu, S.; Zhao, P.; Du, Y. Phase-field simulation of the solidified microstructure in a new commercial 6xxx aluminum alloy ingot supported by experimental measurements. Int. J. Mater. Res. 2018, 109, 91-98. [CrossRef]

14. Wang, K.; Wei, M.; Zhang, L.; Du, Y. Morphologies of Primary Silicon in Hypereutectic Al-Si Alloys: Phase-Field Simulation Supported by Key Experiments. Metall. Mater. Trans. A 2016, 47, 1510-1516. [CrossRef]

15. Greenwood, M.; Shampur, K.N.; Ofori-Opoku, N.; Pinomaa, T.; Wang, L.; Gurevich, S.; Provatas, N. Quantitative 3D phase field modelling of solidification using next-generation adaptive mesh refinement. Comput. Mater. Sci. 2018, 142, 153-171.

16. Yang, C.; Xu, Q.; Liu, B. CPU-accelerated three-dimensional phase-field simulation of dendrite growth in a nickel-based superalloy. Comput. Mater. Sci. 2017, 136, 133-143. [CrossRef]

17. Köhnen, P.; Ewald, S.; Schleifenbaum, J.H.; Belyakov, A.; Haase, C. Cotrolloing microstructure and mechanical properties of additively manufactured high-strength steels by tailored solidification. Addit. Manuf. 2020, 35, 101389.

18. Tangen, S.; Sjølstad, K.; Furu, T.; Nes, E. Effect of Concurrent Precipitation on Recrystallization and Evolution of the P-Texture Component in a Commercial Al-Mn Alloy. Metall. Mater. Trans. A 2010, 41, 2970-2983. [CrossRef]

19. Steinbach, I. Phase-field models in materials Science. Modelling Simul. Mater. Sci. Eng. 2009, 17, 073001. [CrossRef]

20. MICRESS. Version 6.4. Access e.V.: Aachen, Germany. Available online: http://www.micress.de (accessed on 18 May 2020).

21. Eiken, J. A Phase-Field Model for Technical Alloy Solidification. Ph.D. Thesis, RWTH Aachen, Aachen, Germany, 2009.

22. Kang, H.; Li, X.; Su, Y.; Liu, D.; Guo, J.; Fu, H. 3-D morphology and growth mechanism of primary $\mathrm{Al}_{6} \mathrm{Mn}$ intermetallic compound in directionally solidified Al-3at.\%Mn alloy. Intermetallics 2012, 23, 32-38. [CrossRef]

23. Yang, P.; Engler, O.; Klaar, H.-J. Orientation relationship between $\mathrm{Al}_{6} \mathrm{Mn}$ precipitates and the $\mathrm{Al}$ matrix during continuous recrystallization in Al-1.3\%Mn. J. Appl. Cryst. 1999, 32, 1105-1118. [CrossRef]

24. Greer, A.L.; Bunn, A.M.; Tronche, A.; Evans, P.V.; Bristow, D.J. Modelling of inoculation of metallic melts: Application to grain refinement of aluminium by Al-Ti-B. Acta Mater. 2000, 48, 2823-2835. [CrossRef]

25. Apel, M.; Eiken, J.; Hecht, U. Phase field models for heterogeneous nucleation: Application to inoculation in alpha-solidifying Ti-Al-B alloys. Eur. Phys. J. Special Topics 2014, 223, 545-558. [CrossRef]

26. Böttger, B.; Eiken, J.; Schmid-Fetzer, R. Phase field simulation of equiaxed solidification in technical alloys. Acta Mater. 2006, 54, 2697-2704. [CrossRef]

27. Böttger, B.; Eiken, J.; Apel, M. Phase-field simulation of microstructure formation in technical casting-A self-consistent homoenthalpic approach to the micro-macro problem. J. Comput. Phys. 2009, 228, 6784-6795. [CrossRef]

28. Thermo-Calc Software TCAL6 Al-alloys Database. Version 6. Thermo-Calc Software AB: Solna, Sweden. Available online: https://www.thermocalc.com/media/56825/tcal6_extended_info.pdf (accessed on 18 May 2020).

29. Thermo-Calc Software MOBAL5 Al-alloys Mobility Database. Version 5. Thermo-Calc Software AB: Solna, Sweden. Available online: https://www.thermocalc.com/media/56826/mobal5.pdf (accessed on 18 May 2020).

30. Andersson, J.-O.; Helander, T.; Höglund, L.; Shi, P.; Sundman, B. Thermo-Calc \& DICTRA, computational tools for materials science. Calphad 2002, 26, 273-312.

(C) 2020 by the authors. Licensee MDPI, Basel, Switzerland. This article is an open access article distributed under the terms and conditions of the Creative Commons Attribution (CC BY) license (http://creativecommons.org/licenses/by/4.0/). 